\title{
AN APPROACH FOR PREDICATION OF COMPLICATIONS WOMEN FIGHTS DURING MATERNAL PERIOD
}

\author{
Rupali Sawant \\ Research Scholar \\ Thadomal shahani Engineering College \\ Bandra (W) \\ Dr.J.W.Bakal \\ Professor \& Principal,
}

. Shivajirao S. Jondhale College of Engineering, Dombivli (E)

\begin{abstract}
-
Pregnancy and motherhood are natural processes in the lives of women. One of the great feelings for every woman is begin a Mother, but maternal period is very much susceptible for health issues. Some old illnesses may increases or new illnesses can start during this period. Recently Indian health status has improved. Child mortality rates and maternal mortality are declined in current scenario but when Indian situation is compared with other developed countries it is not so good. Advance in data analytics has become one of the driving forces in multiple fields to turn them into technology dependent ones. One of the fields where this impact is still at lower level is maternal health care. There is a need to analyze the symptoms, take steps towards the precautions and dealing with the complication which women fights during this period. This paper discuss various complication women suffer during maternal period, various approaches proposed in past with their findings and it also proposed a model which can be used for predication of parameters which lead to the complication in pregnancy.
\end{abstract}

Keywords- Maternal health, Mortality ratio child mortality, health services, Infant Mortality Rate (IMR)

Cite this Article: Rupali Sawant and Dr.J.W.Bakal, An Approach For Predication of Complications Women Fights During Maternal Period, International Journal of Computer Engineering and Technology, 10(2), 2019, pp. 125-134.

$\mathrm{http}: / /$ iaeme.com/Home/issue/IJCET?Volume=10\&Issue=2 


\section{INTRODUCTION}

Indian health care system is one of the complex and largest sectors. It delivers services across a wide range of geographic and socioeconomic settings. India spends around $4.1 \%$ of GDP on health [19].In reproductive age pregnancy and motherhood is natural processes in the lives of women. A healthy child needs a healthy mother. She should be strong both mentally and physically. Maternal health, malnutrition, the quality of care during maternal period invites most of the diseases for less than five year children. As per UNICEF and WHO 30 million babies need specialized care to survive or born too soon or become sick every year [16]. As per the report of maternal care indicators [17] percentage of women who received antenatal care at urban in the year of 2015-16 has been decline by 1\% compare with the year 2005-06 where as percentage of women who received antenatal care at rural has been increased by $5.6 \%$. Following graph shows Mortality rate, female adult (per 1,000 people) of various country [18].

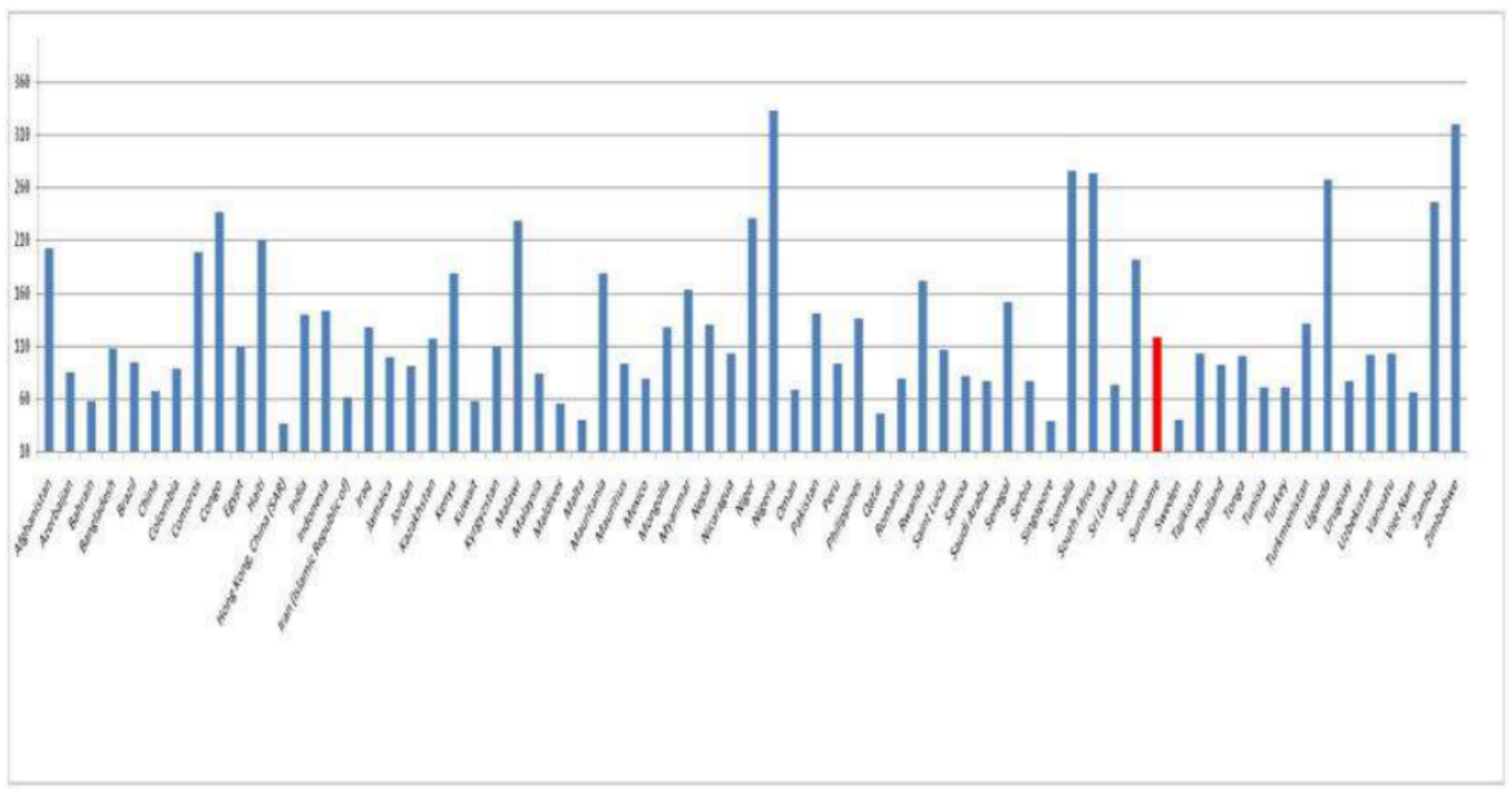

Figure1: Mortality rate, Female adult (per 1,000 people)

As per the census India statistics SRS Reports_2015 [18] MMR rate of India is 139, which is higher than countries like china, Bangladesh, Kuwait, Sri Lanka and many more. As per the report of Neo-Natal Mortality Rates and percentage share of Neo-Natal Deaths to Infant Deaths by residence, India and bigger States, 2015[18] .Maharashtra is higher than Kerala, Himachal Pradesh, Karnataka, Gujarat, Haryana, Punjab and West Bengal in total percentage of Neo-natal death to infant deaths. It is very important to predict challenges and determine the health of the next generation to transform the health status of the country. There is a need to control the postpartum and prenatal mortality rate in Maharashtra. Advance in technology make strides into many fields including health care. Technology has been adopted by the healthcare system since long period however it retrain secondary as far as predication and management of data.

The section below describes various complications women may suffer during maternal period.

\subsection{Complications during preconception}

Set of interventions which aim to modify or identify social, behavioral risks to women health through prevention and management is known as preconception care. Increased in nutrition 
requirements are experience by all women during pregnancy. Hence it is required that every women need to maintain a healthy balanced diet. According to WHO [20] the ratio of unplanned pregnancy is 4 out of 10 women, hence in $40 \%$ of pregnancies essential health intervention is provided too late.

During preconception cares required at;

Mental health -It relate with psychosocial problems. Providing psychosocial counseling and educational before and during pregnancy these can be improve.

Nutritional condition- Nutrition's is required to healing wounds, repairing damage cell, boosting immune system. With the help of supplement and screening these can be improved.

Consumption of Tobacco- Tobacco may damage eggs or sperm. It has direct effect on baby's healths. Hence prevention of this is required during preconception period. Counseling and providing advice can be more effective methods for these preventions.

Genetic condition- Complications and history of genetic risk identification play an important role during preconception. Proper planning and appropriate treatment helps to improve these conditions.

Environmental health- Avoiding pesticide, protecting from lead exposure and education helps to improve this.

\subsection{Complications during prenatal}

For growth of healthy baby prenatal is a very crucial period. Every woman has different symptoms in different phases of her pregnancy as every woman is unique. Mood swing, Headaches, Constipation, Food carving, Nausea with or without vomiting, Temperature change, Bloating, Breast more tense or tighten, Faster heartbeat, Pregnancy glow, Cramping and spotting, Morning sickness, Depression and anxiety, Frequent urination are some early pregnancy symptoms. Symptoms like stomach and uterus are larger but actually not, amenorrhea are found in few women; however there is no specific pregnancy sign. [1]

Few complications women may fight during prenatal periods are,

\subsubsection{Headache}

It is one of the frequently referral from patient during pregnancy. In early stage of pregnancy it can be caused due to increase in volume of blood. It can be a warning sign for woman or her fetus sometime. First and in third trimesters it commonly occurred but it may occur at any time during pregnancy. There are two types of headaches. When pain is actually a diseases is known as primary headache and when it is symptom of another disease it is secondary headache [2]. During Primary Headache there is no significant risk on pregnancy. Tension Type Headache (TTH), Migraine and Cluster Headache are types of primary headache. Risk may occur because of Secondary Headaches. Anesthesia, change in hormonal may lead to secondary headaches during pregnancy [2]. One of the risk factor which can develop secondary headaches is Migraine. There is no significant difference between symptoms of primary and secondary headache.

\subsubsection{Nausea and vomiting}

It commonly occur in 4th week of pregnancy and goes by the 16th week of pregnancy. It is also known as "morning sickness". Commonly fifty to ninety percents of women suffers from this. It can lead to loss of weight and body fluids of pregnant women [3]. Reason for this is not yet known but it associate with diet, age and smoking habit as well as the gender of infant [4] 


\subsection{3 .Deficiency of Vitamin and Minerals}

Before, during and after pregnancy healthy and balance diet is recommended. The health risk of pregnant women and her fetus increases because of the poor nutrition. Healthy diet completes the need of vitamin and minerals but pregnancy and lactation create extra Nutritional demand for some women. For improvement of body function and growth vitamins are useful whereas for maintenance of the body and energy metabolism mineral plays an important role. [5] Some essential vitamin/mineral and there need are as follows;

- Vitamin A- Required for bones and teeth to grow will find in milk, egg and vegetables.

- Vitamin B12- Helps body to use phosphorus calcium and. Source of this is fatty fish and milk.

- Vitamin E- This helps body to use and forms red blood cells. Found in nuts and spinach.

- Vitamin C- It protects tissues from damage and help body to observe iron. Citrus fruits, green beans, Potatoes, broccoli are good sources of vitamin C.

- Folic acid- Help to prevent defect in birth and spinal cord. Can be found in beans and nuts.

- Calcium- This creates healthy bones and teeth. It also helps to prevent blood clots. Yogurt, milk, cheese are sources of calcium.

- Protein- Helps in production of amino acids. We will find this in meat, egg, nuts and been.

\subsection{Complications during postnatal}

Postnatal or postpartum periods begin immediately after the child birth and it refer to the first 6 weeks following childbirth. At most care is required to mother in this period because uterus size and hormone levels of women returns to a non-pregnant state during this period.

Following are few complications women suffer in these periods.

\subsubsection{Material Depression}

Many women after or before the child birth suffer with depression. Depression is nothing but a Mood disorder. It involves changes in brain chemistry. Lack of education of prenatal care is one of the constrained in the treatment of depression [6]. It can range from gentle to severe. Treatment for these symptoms depends on the severity. This can be classified as prenatal, postpartum and postpartum psychosis.[7]

Table 1: Types of depression [7]

\begin{tabular}{|c|c|}
\hline Type & Depression \\
\hline Prenatal & Occurs prior to child birth \\
\hline Postpartum & Occurs in the days weeks or months after delivery \\
\hline Postpartum & Occurs during the first three months after childbirth. \\
\hline
\end{tabular}

Few factors for major depression include:

- Women have a family history of depression or mental illness.

- Women had suffered with stressful events in your life.

- Little or no support from family or friends.

- Eating habit like smoke, drink alcohol. 
Depression can be treated in many different ways. Some of them are; Counseling, Education, Support groups and Medicine.

\subsubsection{Preeclampsia}

It related to high blood pressure. Any women who just deliver a baby may suffer with this. It has same features of hypertensive disorders of pregnancy or preeclampsia without affecting the baby. It consider as a disorder of two components.

1) Greater placental mass or an unidentified signal from the placenta.

2) By her genotype and phenotype aberrant maternal responses it can be determine and can influence by metabolic and physiological changes in pregnancy. [8]

\section{RELATED WORK}

Various related work are studied and their findings are presented in table 2.

Table 2: Related work with findings

\begin{tabular}{|c|c|c|c|}
\hline $\begin{array}{l}\text { Ref. } \\
\text { No. }\end{array}$ & Dataset & Method & Findings \\
\hline 9 & $\begin{array}{l}\text { Data collected from } \\
\text { NHRM-HMIS portal. }\end{array}$ & $\begin{array}{l}\text { Used Tanagra, a data } \\
\text { mining tool. }\end{array}$ & $\begin{array}{c}\text { In Uttar Pradesh, Gujarat, Tamil Nadu, Andhra } \\
\text { Pradesh, Bihar, Madhya Pradesh and Maharashtra } \\
\text { has low ratio of post partum checkups as compared } \\
\text { to other states. } \\
\text { In Bihar, Uttar Pradesh and West Bengal Less } \\
\text { awareness towards postnatal care is major issue. } \\
\text { There is a need to improve Maternal health of India } \\
\text { Different data mining tool can be used for study. }\end{array}$ \\
\hline 10 & $\begin{array}{l}\text { Data collected from } \\
\text { the Texas Birth } \\
\text { Defects Registry. } \\
\text { Use } 16 \text { variables. }\end{array}$ & $\begin{array}{l}\text { Proposed method of a } \\
\text { logistic regression } \\
\text { modeling for high- } \\
\text { dimensional datasets. }\end{array}$ & \begin{tabular}{|c|} 
Risk factors for limb reduction defects. \\
The effectiveness and efficiency of approach of \\
results are shown. \\
142 positive feedbacks have been received from a \\
Statistician and epidemiologists. \\
Identified risk factors in small number were \\
consistent among the automatic approaches. \\
Proved that they are all confounders
\end{tabular} \\
\hline 11 & $\begin{array}{c}600 \text { pregnant women } \\
\text { data was consider for } \\
\text { study. } \\
17 \text { parameters are } \\
\text { considered. }\end{array}$ & $\begin{array}{l}\text { Naive Bayes and C4.5 } \\
\text { classifier use. }\end{array}$ & $\begin{array}{c}\text { C4.5 classifier gives better performance than Naive } \\
\text { Bayes classifier. }\end{array}$ \\
\hline 12 & $\begin{array}{l}\text { Record of } 528,727 \\
\text { births consider }\end{array}$ & $\begin{array}{l}\text { Comparisons by } \\
\text { province, size-for- } \\
\text { gestational-age, } \\
\text { gestational age groups } \\
\text { and maternal condition } \\
\text { at death were } \\
\text { performed. } \\
\end{array}$ & \begin{tabular}{|} 
Due to hypertension and intrauterine growth \\
restriction a high proportion of deaths found in \\
SGA babies. \\
Due to unexplained intrauterine death the \\
maximum proportion of SGA stillbirths were due. \\
Studies required on the association between \\
outcome of SGA and antenatal detection. \\
\end{tabular} \\
\hline 13 & $\begin{array}{l}\text { Data of } 1000 \\
\text { deliveries in Ethiopia } \\
\text { is considered. }\end{array}$ & Chi-square test is used & $\begin{array}{l}\text { From binary logistic regression place of residence, } \\
\text { body mass index (BMI) place of delivery, antenatal } \\
\text { care, anemia level, maternal age, parity, education }\end{array}$ \\
\hline
\end{tabular}




\begin{tabular}{|c|c|c|c|}
\hline 14 & $\begin{array}{c}25 \text { cases of } \\
\text { hypertension with four } \\
\text { attributes. }\end{array}$ & $\begin{array}{c}\text { J48 Decision Tree and } \\
\text { Naïve Bayesian } \\
\text { classifier is used }\end{array}$ & $\begin{array}{c}\text { level and region of residence were found to be } \\
\text { associated with stillbirth. }\end{array}$ \\
\hline 15 & $\begin{array}{c}\text { Compare with Naïve Bayes classifier more accurate } \\
\text { technique is J48 Decision Tree classifier. }\end{array}$ \\
\hline $\begin{array}{c}\text { Data of 25 pregnant } \\
\text { women is considered. }\end{array}$ & $\begin{array}{c}\text { known as Random } \\
\text { Forest }\end{array}$ & $\begin{array}{c}\text { Risk of preeclampsia is increases due to High blood } \\
\text { pressure in pregnancy. } \\
\text { RF results are F-measure indicators }(0.431), \text { ROC } \\
\text { Area (0.731), Kappa statistics }(0.2505)\end{array}$ \\
\hline
\end{tabular}

\section{PROPOSED MODEL}

Following fig. 2 indicate the proposed model. Model consist of three layers.First layer take input from user .cleaning and preprocessing of data done.Then second level look for the specific parameter and store it.Third level run the query to find association between the parameter if any.Asociate parameter display to the user.

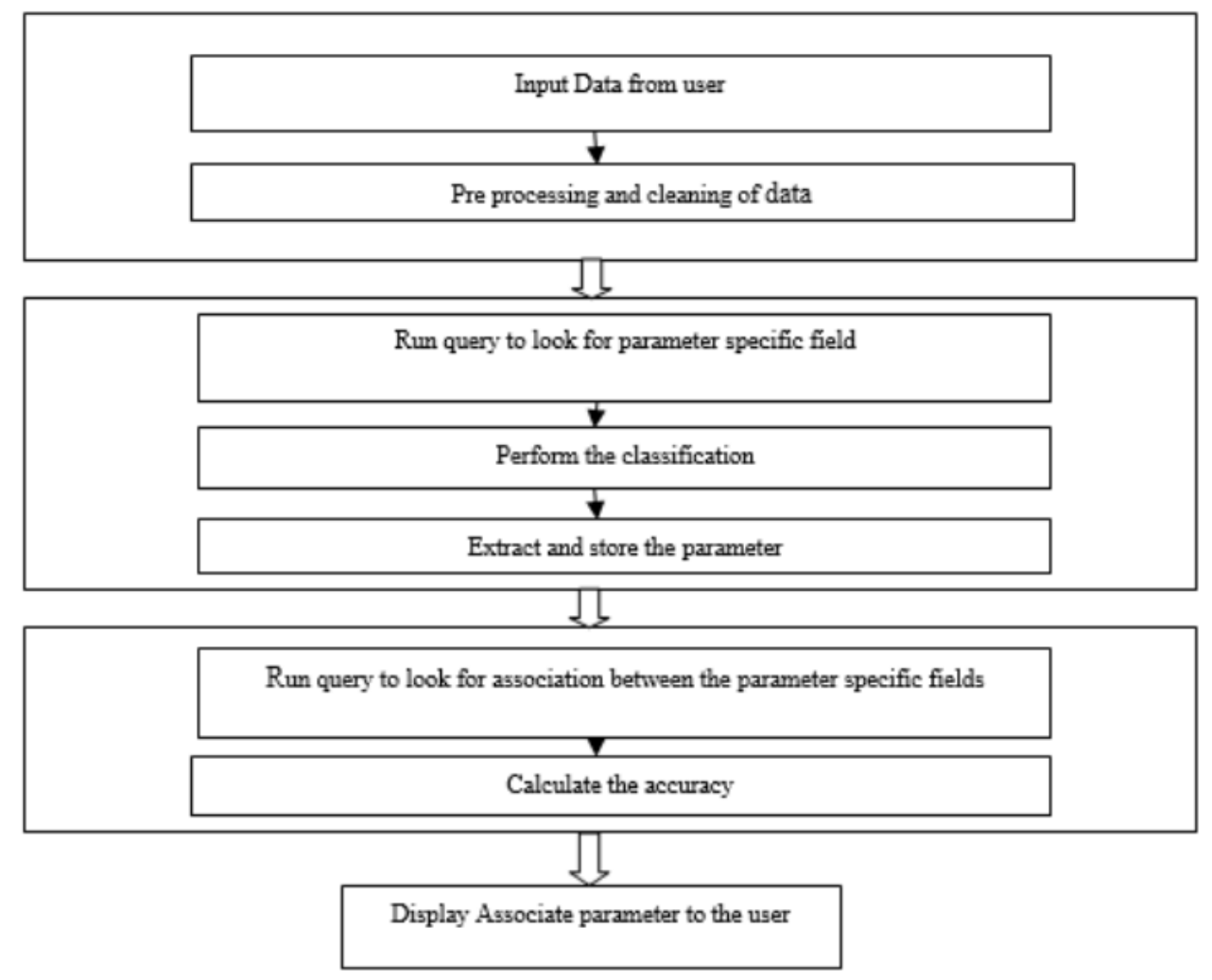

Figure 2:Proposed Model

\subsection{Input Data from user:}

Input : User data.

Output : Data ready for pre-processing.

Impact:To collect all data in proper format.

\subsection{Pre-processing and Cleaning:}

Input : Imported data from user

Output: Consolated data ,process and clean.

Impact:Empty and inconsisten valued are removed. 


\subsection{Run query to look for parameter specific field:}

Input : Process ,clean data

Output:parameter

Impact: Various queries are run to find parameter required for specific field.

\subsection{Perform classification:}

Input: Parameter obtain from previous step.

Output :classified parameter

Impact: This step is required to predict target class for each case given by user.

\subsection{Extarc and store the parameter:}

Input: classified parameter

Output: Collection of parametr from the user query.

Impact :This step is required to increase the accuracy of the system.

\subsection{Run query to look for association between parameter specific field:}

Input : extracted parameter

Output: Relation between parameter.

Impact : This step is required to discover the probability of the co-occurrence of parameter in a collection of data.

\subsection{Calculate the accuracy:}

Input:Data from the previous step.

Output: value of predicted attribute for a new data.

Impact: This step is required to find the ability of classifier to check whether the classified parameter has label properly or not .

\subsection{Display Associate parameter to the user.}

Input: Parameter define scale data from previous step.

Output: Associate parameter

\section{4 .CONCLUSION}

Studies show that current literature and practice is lacking towards the contribution of MMR ratio. A comprehensive effort is required to address the burden of multi mortality which utilizes the information system supported by new computer technology. Current limitation shows unavailability of real, usable data which put a restriction on accuracy of system. There is a need to resolve these issues, before such a project is implemented at a larger scale. Research is required to identify factors which commonly contribute in mortality ratio. This information can help health workers to overseeing, monitoring and taking decision if pregnant women are at high risk.

\section{REFERENCES}

[1] Dian Sa'adlah Maylawat. Muhammad Al Ramdhani, Wldan Budiawan Zulfkar, chsan Taufik, Wahyudin Darmalak sana, "Expert system for predicting the early pregnancy with disorders using artificial neural network" 5th international conference on Cyber and IT Service Management (CITSM), 2017, DOI:10.1109/CITSM.2017. 8089243 
[2] A. Negro ,Z. Delaruelle, T.A. lvanova, S.Khan, R. Omello, B. Raffaelli ,A. Terrn, U. Reuter D. D. Mitsikostas ," Headache and pregnancy: a systematic review" Negro et al. The journal of Headache and pain (2017) DOI 10.1186/s10194-017-0816-0

[3] Mario Festin, Obstetrician Gynaecologist, University of the Philippines Manila," Nause and vomiting in early pregnancy", BMJ Clin Evid. 2009; 2009: 1405.Published online 2009 Jun 3.

[4] Ronna L.Chan, Andrew F. Olshan, David A. Savitz, Amy H. Herring, Julie L., "Maternal influences on nausea and vomiting in early pregnancy", Matern child Health J.2011 ,DOI:10.1007/s10995-009-0548-0.

[5] Mutammimul Ula, Mursyidah, Yana Hendriana, Richki Hardi,” An Expert System for Early Diagnose of Vitamins and Minerals Deficiency On The Body", 2016 International Conference on Information Technology Systems and Innovation (ICITSI) Bandung - Bali, October 24 - 27, 2016 ISBN: 978-1-5090-2449-0

[6] Christie A. Lancaster,Katherine J.Gold,Heather A.Flynn,Harim Yoo,Sheila M.Marcus,Mattew M.Davis,"Risk factors for depressive symptoms during pregnancy:a systematic review",American Journal of obstetrics and Gynecology, January 2010

[7] Ashley Akwa" What is the Importance of Educating Women on Postpartum Depression?" St. Catherine University, Master of Social Work Clinical Research Papers,2015

[8] Sanjay Gupte,Girija Wagh," Preeclampsia-Eclampsia”, J Obstet Gynaecol India,v.64(1); 2014 Feb PMC3931898

[9] Shelly Gupta, Shailendra Narayan Singh, Dharminder Kumar," Empirical Analysis of Maternal Health Data: A Case Study of India”, 2016 2nd International Conference on Next Generation Computing Technologies (NGCT-2016)

[10] Chong Zhang, Jing Yang,F. Benjamin Zhan, Xi Gong,"A Visual Analytics Approach to High-Dimensional Logistic Regression Modeling and its Application to an Environmental Health Study" IEEE Pacific Visualization Symposium 2016

[11] Lakshmi.B.N , Dr.Indumathi.T.S , Dr.Nandini Ravi "Prediction Based Health Monitoring in Pregnant Women" International Conferences on Emerging in Engineering, Science and Technology(ICETEST-2015).

[12] Tina Lavin, David B. Preen and Robert Pattinson," Timing and cause of perinatal mortality for small-for-gestational-age babies in South Africa: critical periods and challenges with Detection", 2016 Springer

[13] Kidanemariam Alem Berhie and Habtamu Gebremariam Gebresilassie," Logistic regression analysis on the determinants of stillbirth in Ethiopia", 2016 Springer

[14] Mario W. L. Moreira ; Joel J. P. C. Rodrigues ; Antonio M. B. Oliveira ; Kashif Saleem ; Augusto Neto," Performance Evaluation of Predictive Classifiers for Pregnancy Care", 2016 IEEE Global Communications Conference (GLOBECOM), 10.1109/GLOCOM.2016.7842136

[15] Mario W. L. Moreira, Joel J. P. C. Rodrigues, Antonio M. B. Oliveira, Kashif Saleem and Augusto J. Venancio Neto ," Predicting Hypertensive Disorders in High-risk Pregnancy Using the Random Forest Approach" 978-1-4673-8999-0/17/\$31.00 (C2017 IEEE

[16] www.who.int

[17] www.mospi.gov.in, "India in Figures 2018"

[18] http://www.censusindia.gov.in/vital_statistics/SRS_Reports_2015.html

[19] National eHealth Authority (NEHA) Report 2015 